International Journal of Engineering \& Technology, $10(1)(2021) 1-7$
International Journal of Engineering \& Technology
SPC
Website: www.sciencepubco.com/index.php/IJET
Research paper

\title{
Science in mobile apps for education: tackling online learning within pandemic outbreak
}

\author{
Nhidayu Kamarudin ${ }^{1} *$, Eileen Ong ${ }^{2}$, WS Chung ${ }^{3}$ \\ ${ }^{1}$ School of Computing and Creative Media University College of Technology Sarawak No 1, Jalan Universiti, Sibu Sarawak \\ *Corresponding author E-mail: hidayu.kamarudin@gmail.com
}

\begin{abstract}
In adapting the issues of pandemic, educational sectors in Malaysia from the lower school level till university levels are encouraged to forecast any specific tools that may help in cater the needs in utilizing online learning. It is by right the issues that been face by global outbreak for everyone on earth as Covid19 that embarked big challenges in face to face and normal daily classes and learning method. Therefore this paper is written to give a general overview, uncover the possible models in used and technologies that may overcome the needs of online education specifically focused for improving the usage of online educational tools especially with the use of mobile application for learning itself. The concept of manual for pen and paper reporting can makes the reporting very slow especially in terms of communication and sharing of information. Plus, within the outbreak patterns may will provide inaccurate information and may also late results to be achieved. This paper is discussing model in plan and the implementation proposed with overcome results of the post results questionnaire conducted to get the major feedback on usage of the current proposed app.
\end{abstract}

Keywords: Mobile Learning; Science; Primary Education; Pandemic; E-Learning.

\section{Introduction}

In the era of mobile technology and everything in hands, mobile devices become a part of our life hence mobile application in the education field will make a major impact and changes. Education is essential to the children because it provides more advantage and knowledge to their life. For example, it can influence an individual become more positive thinking, learn new knowledges and gain proficiency with the aptitudes and capacities. The usage of the smartphone is growing throughout in the world. This is because the smartphone of today become more effective and more functional compared to the mobile phones of back then. The users now spend their free time to use the mobile devices. Mobile devices now not just for calling or texting, it can be function as a computer yet and mobile phones enough to fit in a people's hand. The most of the time that people spend on mobile devices is the mobile application compare on the mobile websites.

Due to the multi-functions of the mobile devices, the mobile devices contain numerous functions are especially suitable for education, so we can boldly try to apply the mobile devices to the education of the primary school, which can improve the teaching content, have the new teaching contents, and make mobile devices become an educational tool[1]. In tackling the pandemic situation especially in catering multi users, and to gain the maximum impact, the usage of mobile educational apps is the possible answer to provide the best solutions between teachers, parents and students. Sung [2] stated by integrating the mobile in learning phases is more effective comparable to traditional methods that using pen-paper or desktop computer. By the development of the proposed mobile apps for learning, it consider that potential technologies are complement to the needs of tackling the pandemic [3].

In particular, mobile applications draws big potential in education. Mobile application now can provide the new learning methods for the student and enhance the communication between parent, teacher and student [4]. From The Star Online, about the mobile application is a new learning method which allows a student to learn the subjects related to their school syllabus at points of interest outside classrooms[5]. In Malaysia, there are plenty of education mobile applications on the Google Play store but the Science-based education mobile application is rarely on the market. So, the development of Science-based education mobile application will be more attractive in the current market. In this study, Science-based education mobile application is developed for the primary school student use and must meet the requirement of the education field. Science-based education mobile application of the primary school student will combine the scientific materials with student's interest, weaken the relevant basic theory teaching from the practical application, reduce the teaching difficulty and allow teachers and parents use together with the student. Starting from the concept of the mobile application, this study introduces the theoretical basis of mobile application in education and teaching, develop an education Science learning mobile application for the primary school student on Android platform and designed based on the Malaysian primary education system. Most of the problem faced by current mobile educational application is that it just solely used for one category of the user which is for student, parent and teacher. It cannot be used by three different users simultaneously. For the educational content in the mobile application, some education mobile application in the Google Play store in Malaysia only given several sets of quiz without giving any topical notes[1] and also some of them only provide the topical notes, not 
provide the quizzes or exercises for the students. Therefore those problem normally exists during the pandemic situation and this prototype of application try to cater the needs of problems found. The usage of mobile learning is currently consider as new trend especially in education fields. As it provides fast accessibility, and due to resilience of the mobile learning itself, those universities are eager to develop their own apps for supporting their education process. Mobile learning may contributes in extending the features of e-learning[6]. The problems of mobile learning includes the theoretical and technological. The social problems that may exists for young learners include the time spent on screen and can hinder social development practice skills[7].Therefore the development of mobile apps learning especially in order to cater the issues within learning practice for pandemic time shall assure that this concepts of educating and skills elevates together.

\section{Proposed mobile application for implementation of education}

As pandemic issues has already changed the way of interaction among teachers and students, perhaps this things also has given tremendous effects to not only to one group of user but it also given new type of norm for the whole world too. Towards the usage of current proposed apps, we can just not only said that this current apps may useful for the students, but also to the teachers and not to forget to the parents/guardian. That is because, the apps will able to be access by three(3) different types of users. For the quiz in education mobile application, the result of the quiz is only shown to the students. Teachers and parents cannot view the result of student result on the quiz. Then, most education mobile application is based on gamification. The gamification will reduce the student's attention and also leading the students to gameplay addiction. Besides that, the education mobile application is more on the App Store in IOS compare to the Google Play Store in Android[8]. Based on the search result in the Google Play store in Malaysia, the content of the education mobile apps that design based on the Malaysia primary school education system and the KSSR model is extremely few.

In within this pandemic issues, as we are advised to be with physical distance, the usage of digital tools already in implementation, that expecting giving more greater benefits as for sure on the mobile application, everyone in used practice social distancing, and by right the application may have better in controlled of research settings, appropriate for field testing, curation and getting user feedback too especially on the education purpose[9]. From the research done by the Bluedot[10], the consumer turns more to mobile apps and in concerns more to limit their contact with on-site staff which about 53\% consumer in America justified for it too.

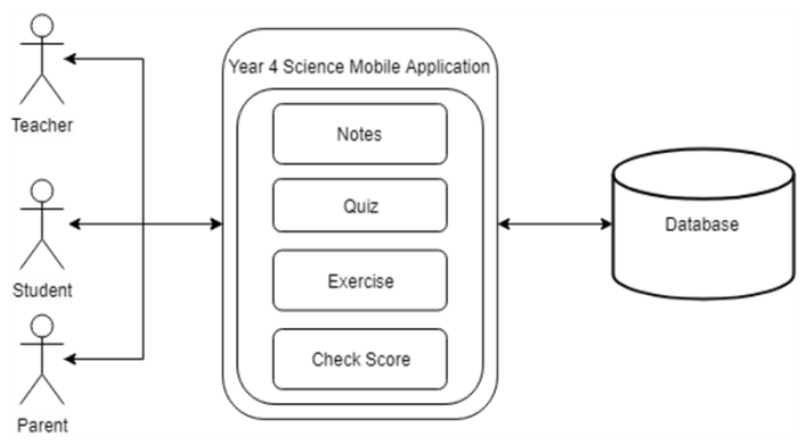

Fig. 2: Shows the Framework for the Year 4 Science Mobile Application.

There have three types of the user, which is the teacher, student and parent. The users can access the Year 4 Science mobile application to read the notes, take the quizzes and exercises and check the score of the quiz. The teacher will be able to edit the questions of the quizzes and exercises by using the Year 4 Science mobile application and the questions were stored in the database. For the student, after the student completed the quiz, the score of the result are stored in the database. The parent will be able to view the student results from the database. Android Studio uses a Gradle-based build system, emulator, code templates, and Github integration. Android Studio contain the emulator for testing mobile application, Gradle for build the android application package (APK) file, code templates for developer to insert code. Each of the projects that create in the Android Studio will contain the modalities that with the source code and resource files. The modalities include Android app modules, Library modules and Google App Engine modules [11].

Android Studio intelligently understanding the changes in the resource of the running application without restart or rebuild the application due to it uses an Instant Run feature to push code and resource changes to a running application [11]. The code editor in Android Studio provides helps to the developer on writing better code and offering completion, refraction, and analysis of the code. After finish on the development of the application, the applications are then compiled into the APK format [11].The emulator in Android Studio enable the developer to test the application looks like in devices like a smartphone. It allows the developer to test the application on different configuration devices such as smartphones, tablets, smartwatches and so on to help the developer shorten the development lifecycle and increase the efficiency ("Top 10 Features of Android Studio_Android Development Course from Experts," 2018).

\section{Understanding the needs of proposed application}

Before the development of the project, a short questionnaire survey is made to gather data from the target audience. In this project, the questionnaire is created using Google Forms and about 32 respondents answering through online. The Google Forms is an online survey application developed by Google that allows the developer to collect the data through the online. This Google Form is developed to cater finding of mobile apps usage before the pandemic issues arises. Since Google Forms can automatically generate the graphs of the data collected in the table. Through the graphs of the data collected, the developer can understand and analyze the requirement from the target audience. In this survey, three sets of questionnaire survey are prepared for the target audience. The target audience of this questionnaire survey is the students, teachers and parents. The total number of the audience that have mobile device at home will show on the Figure 3.0 below. In the questionnaire survey, there have 100 percent of the audience that using the mobile device. 
User who have mobile device

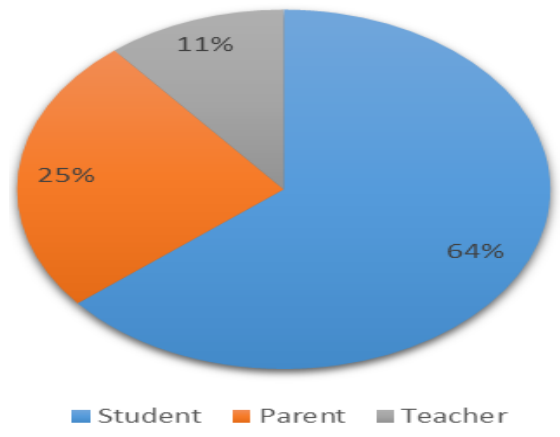

Fig. 3: Number of Audience Who Have Mobile Device.

Do you using the education mobile application for education?

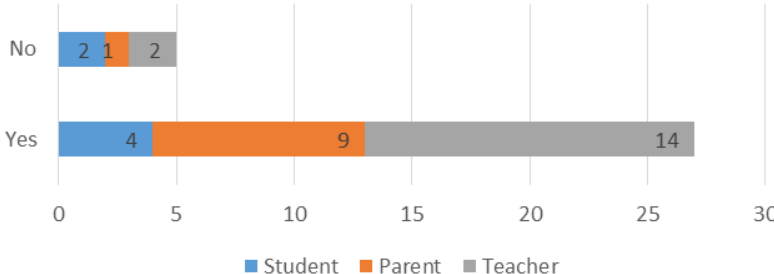

Fig. 3.1: Number of Audience Want Using the Education Mobile Application for Education.

Most of the audiences that can accept using the education mobile application through the result shown in Figure 3.0 and Figure 3.1. As a result, there have around 27 persons of the total audience can accept the education mobile application and 5 persons cannot accept the education mobile application. So, the education mobile application has great acceptance on the market.

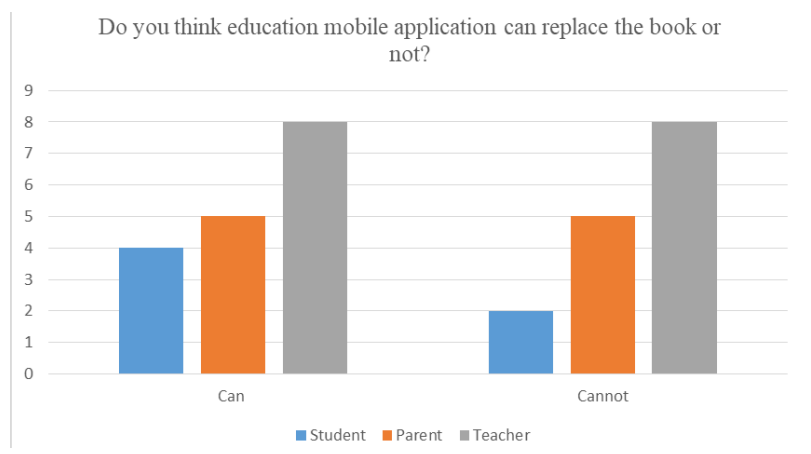

Fig. 3.2: Number of Audience Think About Replace Book by Education Mobile App.

While Figure 3.2 display the audience that thinks about the education mobile application that can replace by the book or not. Based on the result, there have 4 students can accept it and 2 students cannot accept that book can be replaced by the education mobile application. Then, for the parent and teacher, they have the almost same result on this section with 50 percent of them think that the book can be replaced by the education mobile application and another 50 percent of them think that the book can be replaced by the education mobile application and another 50 percent of the audience think that it cannot be accepted.

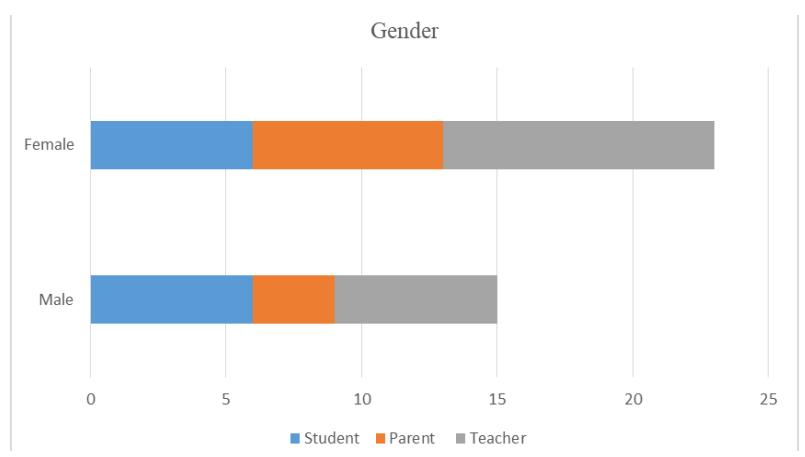

Fig. 3.3: Gender of Target Audience. 


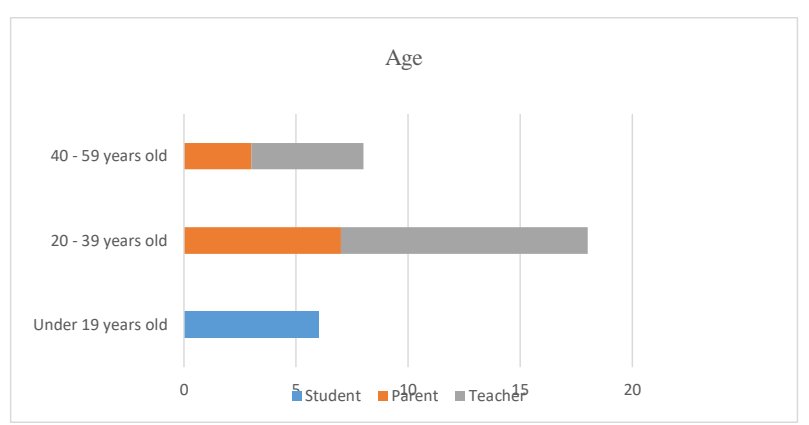

Fig. 3.4: Age of Target Audience.

For Figure 3.3 and Figure 3.4 show the results of the gender and age of the audience that are collected from the questionnaire survey. The total number of audiences joining in this questionnaire survey was 32 people. In these 32 people, there were 15 people are male and 23 people are female. The age is divided into three categories which is under 19 years old, around 20 to 39 years old and 40 to 59 years old. According to the data collected in the Figure 3.4, there are 6 people under the age of 19 years old, 18 people between the ages of 20 to 39 years old, and 8 people between the ages of 40 to 59 years old.

\section{Implementation of the mobile learning application}

In order to approve the significant studies towards this developed mobile learning apps, we already developed an application towards Science for Primary level Year 4. By the development of the current application, it is wish that the technological swift will create an impact and influence with the environment and society too. Within deep consideration and discussion, it is wish that certain situational issues for the online mobile learning apps are sorted.



Fig. 4: Age of Target Audience.

Figure 4.0 above shows the registration and login page for the teachers. The login page allows the teachers to fill in the email, password and Personal Identification Number (PIN) to access the Year 4 Science mobile application. For the registration page, the teachers who does not have the user account for login purpose, they will need to create a new account. The registration page requires the teachers to fill in the full name, email, password and the specific PIN. The PIN is only available to the teachers so only the teachers can access the teacher login page and registration page.
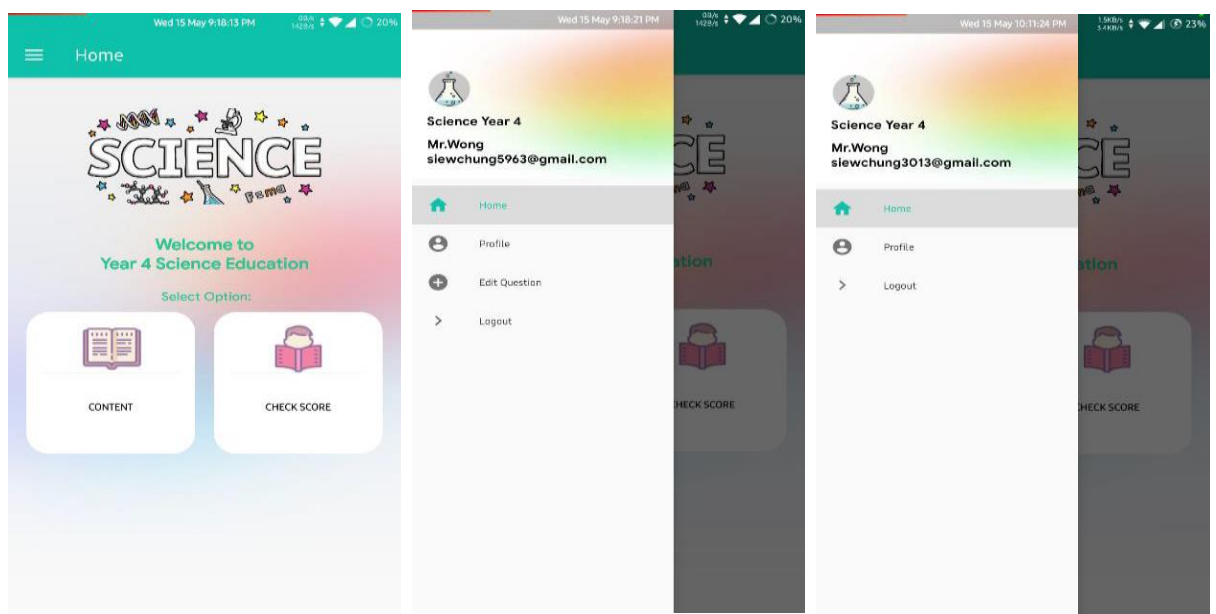

Fig. 4.1: Homepage of the Mobile Learning Application. 
The home page of the teachers and parents consists of the content and checks scores button as depicted in Figure 4.1. The check score button allows the teachers and parents to check the student's quizzes score. Then, the menu of the sidebar navigation drawer for the teachers and parents consists of home, profile and log out options. The teachers have an extra option compared to the parents. It is an edit questions option and allows the teachers to edit the questions of the quizzes.
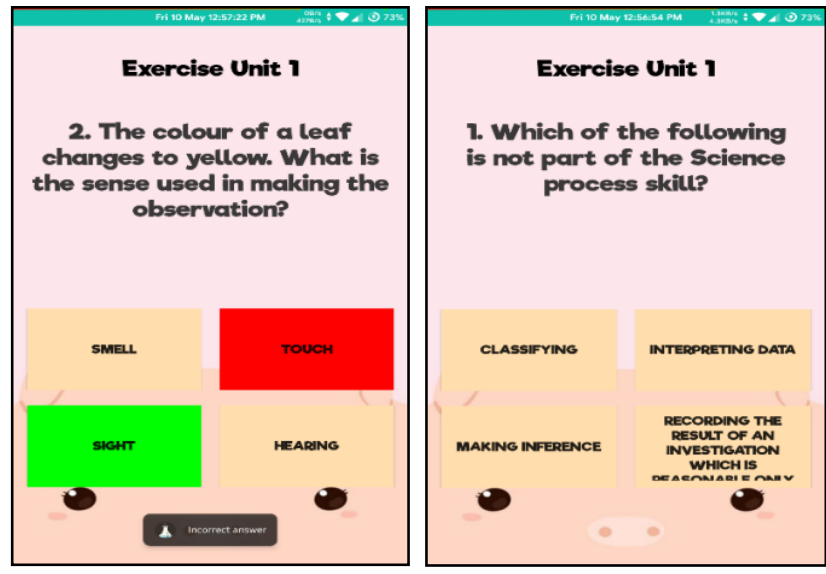

Fig. 4.2: Exercise Page.

While for Figure 4.2 shows the exercise of the Year 4 Science mobile application. The exercise question will be provided to the students for answers. If the students answer the correct answer, the answer will become green color and display the toast to inform that the students that it is the correct answer. If the students answer the incorrect answer, the answer turn to red color and show the toast with the incorrect answer, then it shows the green color of the correct answer to tell the students that this is the correct answer. After the students answered all the question, it will process to the next question automatically. After finishing all the questions, it will return back to the chapter page.

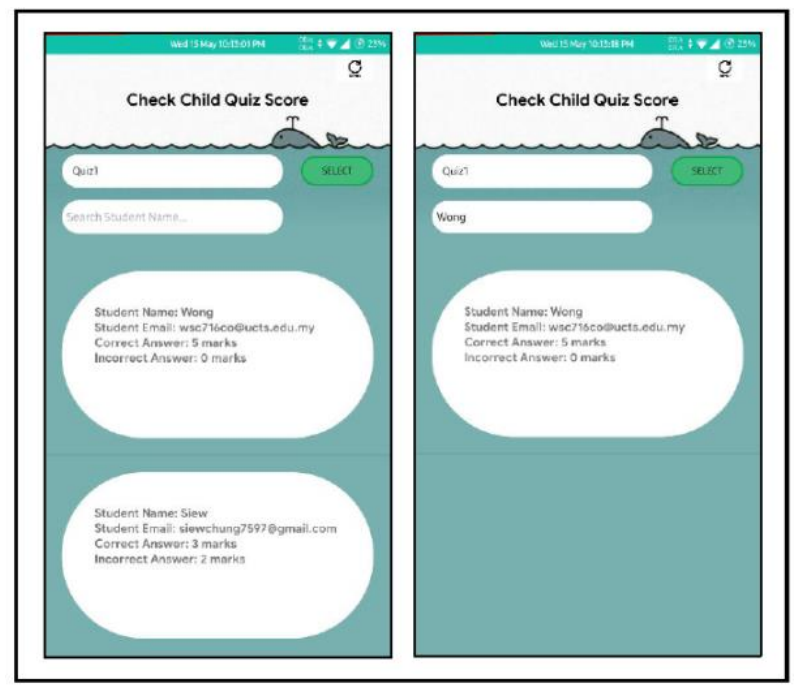

Fig. 4.3: Score page (Students) for Teacher.

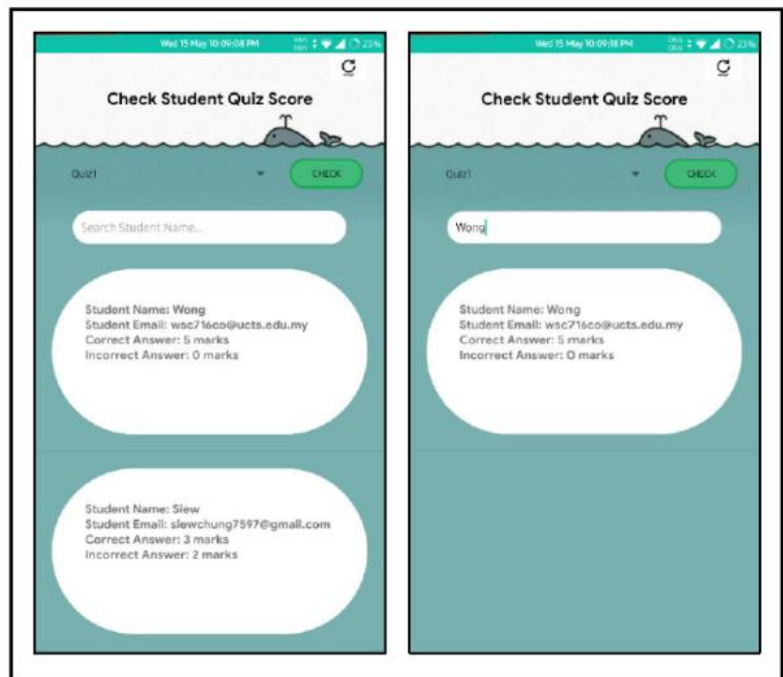

Fig. 4.4: Child Score Page (Parents). 
Figure 4.3 and Figure 4.4 shows the check score page for the teachers and parents. Teachers and parents can check the quiz's score of the students by selecting the quiz number through the check score page. And then, the check score page can allow the teachers and parents to enter the student's name on the search bar to find a certain student to view the score

\section{Post analysis for the mobile application developed}

In order to get the understandings on the acceptance level of the usage of proposed apps among the user, our research has conducted a post development questionnaire that be distributed to seven (9) audiences just to ensure that they have specific understanding on the current application, their opinion towards the usage of the application comparatively to usage of textbook in the classroom and the improvement concepts of learning by using the current applications. Below are some of the related findings as presented in Figure 4.5, 4.6 and 4.7?

Use Year 4 Science mobile application in the classroom



- Agree misagree

Fig. 4.5: Chart for the Number of the Audience Who Agree and Who Disagree with the Year 4 Science Mobile Application Use in the Classroom.

Number of audiences who agree and who disagree with using the Year 4 Science mobile application to study in the classroom is depicted as in Figure 4.5. For the result, there have 6 people agree the Year 4 Science mobile application use in the classroom and 3 people disagree about it. The main reason that the people who disagree that the Year 4 Science mobile application use in the classroom is the smartphone cannot bring to the school so the mobile application will not available to use in the classroom.

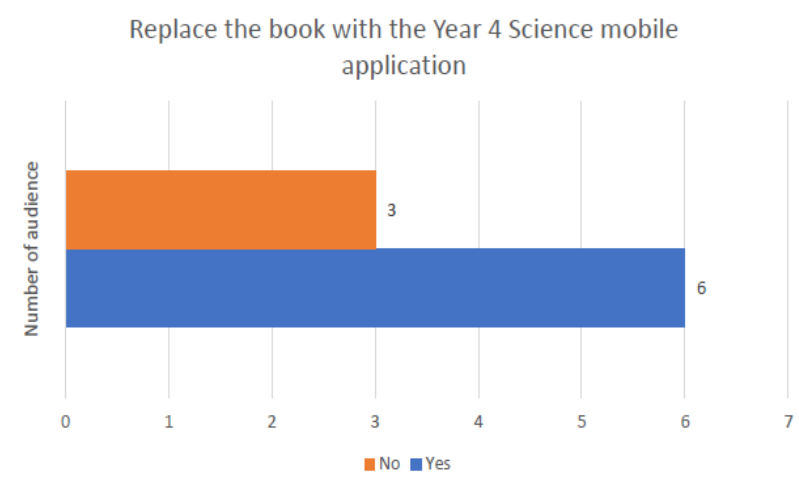

Fig. 4.6: Total Number of Audience in Prefer to Replace Book Instead of Mobile Application.

Based on the result from the Figure 4.6, there have 6 people accept that the Year 4 Science mobile application can replace the book and around 3 people cannot accept it. Those who disagree that the Year 4 Science mobile application can replace the book is because the book can be brought anytime anywhere compared to the mobile application on the smartphone and the smartphone requires charging if its battery ran out.

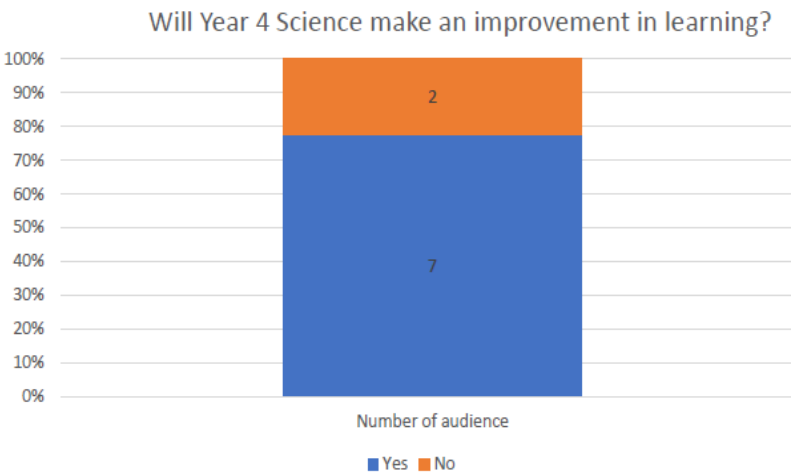

Fig. 4.7: Total Number of Audience in Preference for Application in Used As Improvement for Leaning.

Through the Figure 4.7 above, it is found that there have 7 people think that the Year 4 Science mobile application can make an improvement in learning and another 2 people think that it cannot make an improvement in learning. Based on the feedback from the disagree people, they realized that the smartphone will distract the attention of the students during their study and focus on other application on the 
smartphone like games. So, due to the reason mentioned above, people think that the Year 4 Science mobile application cannot make an improvement in learning.

\section{Conclusion}

The usage of terms for 'contactless commerce' are really significant for this mobile apps with learning as the impact are beyond the cash; due to the current state of the world is not allowed for human touch, by having the application in hands and able to be access within different scope of user will contribute to big appreciation especially in the education world[12]. In order to gather the interest among students, teachers and parents for the use of current mobile apps also need to really expose and accept the technology as it is without hesitation. Of course the technology of mobile apps and education is not really well in acceptance by all consumer or targeted audience but by far with the breakthroughs of the technology and the way we tried to adapt in in our new norm, the hard pain will slowly reduce. The gap between technology barrier and consumer or audience will be smaller and finally it can be assimilate in our new norm especially in this pandemic situation. By far, from the post questionnaire distributed to the audience, by majority, most of them agreed to utilize the apps as improvement apps for learning, prefer to use the apps over the textbook and 70\% agreed to use the apps in the current classroom. That shows the current proposed apps are successfully accepted by all types of user.

\section{Acknowledgement}

This project is fully produced by our student from University College of Technology Sarawak and the publication are fully supported by the University Grant.

\section{References}

[1] Gktalk_imran. (2018). Science Questions Answers - Google Play. (https://play.google.com/store/apps/details?id=com.gktalk.science_questions_an swers).

[2] Sung, Y. T., Chang, K. E., \& Liu, T. C. (2016). "The effects of integrating mobile devices with teaching and learning on students' learning performance: A meta-analysis and research synthesis", Computers and Education, 94, 252-275. https://doi.org/10.1016/j.compedu.2015.11.008.

[3] Madurai Elavarasan, R., \& Pugazhendhi, R. (2020)," Restructured society and environment: A review on potential technological strategies to control the COVID-19 pandemic," Science of the Total Environment, (xxxx), 138858. https://doi.org/10.1016/j.scitotenv.2020.138858.

[4] Roy, S. (2017),"5 Benefits of Using Mobile Apps in Education - eLearning Industry," (https://elearningindustry.com/mobile-apps-in-education-5benefits).

[5] Spykerman, N. (2017).” More to fun lessons - Education,” - The Star Online. (https://www.thestar.com.my/news/education/2017/05/14/more-tofun-lessons/.

[6] Elkhateeb, M., Shehab, A., \& El-bakry, H. (2019),” Mobile Learning System for Egyptian Higher Education Using Agile-Based Approach,” 2019. https://doi.org/10.1155/2019/7531980.

[7] Al Said, N. (2020),'Mobile Application Development for Technology Enhanced Learning: An Applied Study on the Students of the College of Mass Communication at Ajman University," International Journal of Emerging Technologies in Learning (IJET), $15(08), 57$. https://doi.org/10.3991/ijet.v15i08.12551.

[8] Nicol, W. (2018), Get Smart: The Best Educational Apps for iPhone and Android. (https://www.digitaltrends.com/mobile/best-educational-apps/).

[9] Drew, D. A., Nguyen, L. H., Steves, C. J., Wolf, J., Spector, T. D., Chan, A. T., \& Consortium, C. (2020),"Rapid implementation of mobile technology for real-time epidemiology of COVID-19,"MedRxiv, 0473(May), 2020.04.02.20051334. https://doi.org/10.1101/2020.04.02.20051334.

[10] Bluedot.io (2020) https://bluedot.io/library/state-of-what-feeds-us-restaurants-covid-19/.

[11] Rouse, M. (2011). What is iterative development_- Definition from WhatIs. (https://searchsoftwarequality.techtarget.com/definition/iterative-development).

[12] Leary, D. E. O. (2020). Evolving Information Systems and Technology Research Issues for COVID-19 and Other Pandemics Evolving Information Systems and Technology Research Issues for. Journal of Organizational Computing and Electronic Commerce, OO(00), 1-8. https://doi.org/10.1080/10919392.2020.1755790. 